\title{
$\gamma$-AMINOBUTYRIC ACID CONCENTRATION, L-GLUTAMATE 1-DECARBOXYLASE ACTIVITY, AND PROPERTIES OF THE $\gamma$-AMINOBUTYRIC ACID POSTSYNAPTIC RECEPTOR IN COBALT EPILEPSY IN THE RAT ${ }^{1}$
}

\author{
STEPHEN M. ROSS ${ }^{2}$ AND CHARLES R. CRAIG ${ }^{3}$
}

Department of Pharmacology and Toxicology, West Virginia University Medical Center, Morgantown, West Virginia 26506

\begin{abstract}
Crude mitochondrial synaptosomal $\left(\mathrm{P}_{2}\right)$ fractions were used to measure L-glutamate 1-decarboxylase (GAD) activity, and crude synaptic membranes were isolated from rat brains and used to determine $\gamma$-aminobutyric acid (GABA) concentration and postsynaptic GABA receptor binding characteristics in rats with cobalt, copper, or glass implanted in right and left cerebral cortices. Copper was employed as a positive metal control because it elicits a morphological profile similar to that of cobalt but is non-epileptogenic. From tissue adjacent to the lesion, GAD activity was assessed by counting trapped ${ }^{14} \mathrm{CO}_{2}$ liberated from $\left[{ }^{14} \mathrm{C}\right]$ glutamate and was reduced maximally to $25 \%$ of glass controls 7 days following cobalt insult, a period of peak seizure incidence. No reduction in GAD activity was observed 1 or 21 days after cobalt treatment or at any time period in copper- or glasstreated animals. A radioligand $\left[{ }^{3} \mathrm{H}\right] \mathrm{GABA}$ receptor assay was utilized to determine GABA levels, postsynaptic receptor number $\left(B_{\max }\right)$, and the affinity of the postsynaptic receptor for the ligand $\left(K_{D}\right)$ in tissue surrounding the lesion. GABA concentration was reduced maximally to $47 \%$ of glass controls 7 days following cobalt implantation. Scatchard plot analysis of tissue adjacent to the cobalt lesion revealed a significant increase in apparent receptor density $\left(B_{\max }\right)$ to $200 \%$ of glass controls 7 days after bilateral cobalt implantation $\left(\boldsymbol{B}_{\max }=3.97 \pm 0.83 \mathrm{pmol} / \mathrm{mg}\right.$ of protein, cobalt versus 1.36 \pm 0.17 , glass control). Moreover, at 7 days, no change in kinetic parameters was noted after copper treatment. From days 7 to 21 , the density $\left(B_{\max }\right)$ of postsynaptic GABA receptors in cobalt-treated tissue appears to return slowly to glass control values. Results from the present study suggest that degeneration of the GABA pathway in the frontal cortex of the cobalt-epileptic rat occurs and, coupled with the increased $B_{\max }$, may represent a "denervation supersensitivity" phenomenon.
\end{abstract}

The chronic model of epilepsy produced in the rat by administration of cobalt to the cerebral cortices has been widely studied and appears to be a suitable model for the study of neurochemical changes associated with a chronic seizure disorder.

In addition to its chronicity and paroxysmal nature, characteristic electroencephalogram (EEG) changes, and increased susceptibility to central nervous system (CNS) convulsants, there are also other similarities between cobalt epilepsy and human epilepsy. Certain anticonvul-

This work was supported by the West Virginia University Medical Corp., National Institutes of Health Biomedical Research Grant 5-S07RR05433-18, and National Institute of General Medical Sciences Predoctoral Training Grant 5 T32 GM 07039-05. A preliminary report of this work has appeared previously (Ross, S. M., and C. R. Craig (1981) Toxicologist 1: 50).

${ }^{2}$ Present address: Albert Einstein College of Medicine, Institute of Neurotoxicology, Bronx, NY 10461.

${ }^{3}$ To whom correspondence should be addressed. sants are able to attenuate seizures in both (Van Duijn and Visser, 1972; Craig et al., 1976a). Craig and Hartman (1973) also showed that the same amino acids found to be decreased in the brain of humans with epilepsy (Van Gelder et al., 1972) were decreased in the brains of cobaltepileptic rats.

Several studies have shown an altered neurochemistry in this experimental seizure model. Hoover et al. (1977a) demonstrated that acetylcholine was depressed at the time of peak seizure activity, extending the observation of Goldberg et al. (1972) that both the synthetic enzyme, choline acetyltransferase, and the degradative enzyme, acetylcholinesterase, were depressed 7 days following cobalt implantation.

Several investigaturs (Van Gelder, 1974; Van Gelder and Courtois, 1972; Koyama, 1972; Altamura et al., 1978) have been concerned with changes in $\gamma$-aminobutyric acid (GABA) and/or the synthetic enzyme, L-glutamate 1-decarboxylase (GAD), in cobalt epilepsy. Emson and Joseph (1975) showed that GABA, glutamate, and aspar- 
tate were reduced in the area of the lesion but that no change occurred in glycine or glutamine levels. They also studied the activation of the transmitter-related enzymes, glutamate decarboxylase, acetylcholinesterase, choline acetyltransferase, and aromatic amino acid decarboxylase, and showed significant reductions 4 to 8 days following cobalt implantation with a subsequent recovery to normal levels by 24 days. Emson and Joseph concluded that cobalt-induced epilepsy in the rat is associated with a relatively selective loss of neuronal tissue. This selectivity is the reason for using this model in an attempt to gain a better understanding of seizure processes in general.

\section{Materials and Methods}

\section{Animals}

Male Sprague-Dawley rats weighing 150 to $280 \mathrm{gm}$, obtained from Zivic Miller Laboratories, were utilized in these studies. The animals were housed in the West Virginia University Medical Center Animal Quarters for approximately 7 days prior to use. During this period, all rats were exposed to alternating light-dark cycles and constant temperature and had free access to food and water.

\section{Surgery}

Rats were anesthetized with sodium pentobarbital (35 $\mathrm{mg} / \mathrm{kg}$, i.p.) and placed in a stereotaxic frame. The dura mater was exposed over the right and left frontal cortices ( $3 \mathrm{~mm}$ lateral to the sagittal suture and $2 \mathrm{~mm}$ rostral to the bregma), and the dura and pia mater were punctured with a needle. A cobalt rod (1 to $2 \mathrm{~mm}$ long and $1 \mathrm{~mm}$ in diameter), copper wire, or a glass bead of about the same size then was inserted into the cortex. After completion of surgery, the rats were housed in cages in groups of six and maintained on a 12-hr light-dark cycle with food and water ad libitum.

\section{GAD assay}

Tissue preparation. Following decapitation, the cerebral cortex was dissected and placed in $0.32 \mathrm{~m}$ sucrose. The tissue was blotted dry on Whatman No. 1 filter paper, weighed, and placed in $10 \mathrm{vol}$ of $0.32 \mathrm{M}$ sucrose at $0^{\circ} \mathrm{C}$. The tissue was hand-homogenized with a glassTeflon homogenizer (12 to 13 strokes) and centrifuged at $1,000 \times g(3,000 \mathrm{rpm})$ for $15 \mathrm{~min}$. The supernatant $\mathrm{S}_{1}$ was saved and the pellet $P_{1}$ was discarded. $S_{1}$ was centrifuged at $4,800 \times g(2,000 \mathrm{rpm})$ for $10 \mathrm{~min}$. $\mathrm{P}_{2}$ was saved and $\mathrm{S}_{2}$ was discarded. Next, the pellet $\mathrm{P}_{2}$ was reconstituted in $10 \mathrm{vol}$ of Krebs-Ringer phosphate buffer (KRP) by agitating briefly with a Vortex mixer or Polytron. The resultant suspension was centrifuged at $48,000 \times g$ for 10 min. The pellet $P_{3}$ was reconstituted in 10 vol of KRP and $\mathrm{S}_{3}$ was discarded. Again, the resultant suspension was centrifuged at $48,000 \times g$ for $10 \mathrm{~min}$. $\mathrm{P}_{4}$ was saved and reconstituted in $10 \mathrm{vol}$ of KRP. To insure proper mixing of buffer and tissue, the suspension was agitated with a Vortex mixer prior to removal of an aliquot for the $\mathrm{GAD}{ }^{14} \mathrm{CO}_{2}$ assay.

Composition of buffers and cofactors for the GAD assay. A total volume of $1 \mathrm{ml}$ was used for the assay: 800 $\mu \mathrm{l}$ of Krebs-Ringer phosphate buffer (pH 7.4), $100 \mu \mathrm{l}$ of lissue suspension, and $100 \mu \mathrm{l}$ of cofactor and substrates (pH 7.4). The composition of KRP was (in millimolar concentrations): $\mathrm{NaCl}, 1.26 ; \mathrm{KCl}, 4.75 ; \mathrm{CaCl}_{2}, 1.27 ; \mathrm{MgCl}_{z}$. $6 \mathrm{H}_{2} \mathrm{O}, 1.42 ; \mathrm{NaH}_{2} \mathrm{PO}_{4} \cdot \mathrm{H}_{2} \mathrm{O}, 15.8$; and anhydrous dextrose, $2 \mathrm{mg} / \mathrm{ml}$. Substrate and cofactor concentrations in the final 1 -ml volume were pyridoxol 5 -phosphate, 0.5 $\mathrm{mM}$; reduced glutathione, $0.5 \mathrm{mM}$; glutamate, $20 \mathrm{~mm}$; $\left[{ }^{14} \mathrm{C}\right]$ glutamate, $4 \mu \mathrm{M}$; and amino-oxoacetic acid, $0.06 \mu \mathrm{M}$.

Materials and GAD assay conditions. A 7-ml Vacutainer tube (Becton-Dickinson) was used as the reaction vessel. A wire was inserted into the bottom of each rubber stopper and twisted into a loop, and Whatman No. 1 filter paper $(0.6 \times 2 \mathrm{~cm})$ was attached to the loop. Next, $30 \mu \mathrm{l}$ of Hyamine hydroxide (methylbenzethonium hydroxide, $\sim 1.0 \mathrm{M}$ in methanol) was dripped onto the filter paper and permitted to dry. Enzymatic activity was initiated by placing a 100- $\mu \mathrm{l}$ aliquot of tissue suspension into the reaction vessel containing KRP buffer (previously bubbled with $95 \% \mathrm{CO}_{2}, 5 \% \mathrm{O}_{2}$ for 5 to $10 \mathrm{~min}$ ), substrate, cofactors, and $20 \mu \mathrm{l}$ of $\left[1-{ }^{14} \mathrm{C}\right]$ glutamate (final concentration, $4 \mu \mathrm{M}$; specific activity, $0.1 \mu \mathrm{Ci} / \mathrm{mol}$ ). Immediately after the addition of tissue to the reaction vessel, the rubber stopper, to which filter paper coated with Hyamine hydroxide was attached, was placed directly into the Vacutainer tube containing the reactants and agitated with a Vortex mixer. Care was taken not to touch the Hyamine hydroxide-coated filter paper to the Vacutainer wall.

The reaction was allowed to continue for $30 \mathrm{~min}$ at $37^{\circ} \mathrm{C}$ in a shaking Dubnoff water bath. Termination of the enzyme activily was accomplished by injecting $50 \mu \mathrm{l}$ of $3 \mathrm{M}$ sulfuric acid (27 gauge needle) through the Vacutainer stopper without permitting the acid to touch the filter paper or wire. The acid inhibits GAD activity and also liberates trapped ${ }^{14} \mathrm{CO}_{2}$. After an equilibration period of $1 \mathrm{hr}$, the rubber stopper with wire and filter paper attached was removed. The filter paper was carefully taken from the wire and placed in a scintillation vial to which $10 \mathrm{ml}$ of scintillation cocktail was added.

GAD kinetics. Preliminary experiments demonstrated linearity of GAD activity for more than 45 min using a $100-\mu \mathrm{l}$ aliquot $(20 \mathrm{vol})$ of tissue suspension. GAD activity was also linear using up to at least $200 \mu \mathrm{l}(20 \mathrm{vol})$ of the $\mathrm{P}_{2}$ fraction at $37^{\circ} \mathrm{C}$. All GAD studies were run for $30 \mathrm{~min}$ using a $100-\mu \mathrm{l}(20-\mathrm{vol})$ aliquot of tissue at $37^{\circ} \mathrm{C}$.

\section{GABA receptor binding}

Tissue preparation. Rats were decapitated, and the brains were removed rapidly and homogenized in $15 \mathrm{vol}$ of $0.32 \mathrm{~m}$ sucrose using a Teflon-glass homogenizer (12 to 13 hand strokes). Next the tissue was centrifuged at 1,000 $\times g(3,000 \mathrm{rpm})$ for $10 \mathrm{~min}$ and was prepared essentially according to the method of Enna and Snyder (1977).

The supernatant $S_{1}$ was saved and the pellet $P_{1}$ was discarded. $S_{1}$ was centrifuged at $20,000 \times g(13,000 \mathrm{rpm})$ for $20 \mathrm{~min} . \mathrm{S}_{2}$ was discarded and $P_{2}$ was saved. Next, 10 $\mathrm{ml}$ of cold distilled water was added to $\mathrm{P}_{2}$ and dispersed with a Polytron for 30 sec. Cold distilled $\mathrm{H}_{2} \mathrm{O}$ was added to fill the centrifuge tube, the tube was centrifuged at $8,000 \times g(8,250 \mathrm{rpm})$ for $20 \mathrm{~min}$, and $\mathrm{S}_{3}$ and $\mathrm{P}_{3}$ were saved. After washing the precipitate with the superna- 
tant, the precipitate was discarded, the supernatant $S_{3}$ was centrifuged $(48,000 \times g)$ for $10 \mathrm{~min}$, the resultant supernatant was discarded, and the precipitate was again dispersed in cold water and centrifuged as above. The final pellet was saved and frozen.

After freezing the pellet for at least $24 \mathrm{hr}, 15 \mathrm{ml}$ of Tris/citrate buffer ( $\mathrm{pH} 7.1$ ) was added to the frozen pellet and dispersed with a Polytron for $45 \mathrm{sec}$ (setting 6). The volume was brought to the top of the tube with $0.05 \mathrm{M}$ Tris/citrate buffer and transferred to a $400-\mathrm{ml}$ beaker. A $10 \%$ initial dilution of Triton X-100 in a volume of 250 $\mu \mathrm{l}$ was added to the beaker $(250 \mu \mathrm{l}$ of $10 \%$ Triton $\mathrm{X}-100$ to each $50 \mathrm{ml}$ of tissue suspension). The beaker was immediately shaken and incubated at $37^{\circ} \mathrm{C}$ for $30 \mathrm{~min}$ in a shaking water bath. At the end of the incubation period, the contents of the beaker were transferred to two tubes and centrifuged at $48,000 \times g$ for $10 \mathrm{~min}$. The supernatant was discarded and the pellet was saved. Twenty-five milliliters of Tris/citrate buffer $(0.05 \mathrm{M})$ was added to the pellet and dispersed with a Polytron to disrupt the pellet. Again, the tissue suspension was centrifuged at $48,000 \times$ $g$ for $10 \mathrm{~min}$, the resultant supernatant was discarded, and the pellet was saved. Tris/citrate buffer was added to the pellet, dispersed with a Polytron, and centrifuged at $48,000 \times g$ for $10 \mathrm{~min}$. The supernatant was discarded and the pellet was saved. These centrifugation steps removed the Triton $\mathrm{X}-100$ and any remaining endogenous GABA. Fifty milliliters of $0.1 \mathrm{~m}$ Tris/citrate was added to the remaining pellet and disrupted with a Polytron to generate an evenly dispersed tissue suspension. This suspension (crude synaptic membranes) was used for subsequent assays.

Sample preparation for determination of endogenous $G A B A$ in brain tissue. The animals were killed by microwave irradiation using a focused beam to the skull for $10 \mathrm{sec}$. The brains were dissected rapidly, immersed in liquid nitrogen, and blotted dry. The frontal cerebral cortex adjacent to the lesion was removed and weighed. The tissue was placed immediately in $20 \mathrm{vol}$ of ice cold $\mathrm{H}_{2} \mathrm{O}$, dispersed with a Polytron (setting 6) for $30 \mathrm{sec}$, and centrifuged at $48,000 \times g$ for $10 \mathrm{~min}$. Without disturbing the pellet, a fraction of the supernatant was removed and diluted to the appropriate volume with ice cold distilled $\mathrm{H}_{2} \mathrm{O}$. In all cases, dilutions were designed to produce $50 \%$ displacement of the binding curve when a $20-\mu \mathrm{l}$ aliquot was added to the reaction mixture.

$G A B A$ binding assay. To 16-ml Sorvall centrifuge tubes, $1 \mathrm{ml}$ of cold distilled $\mathrm{H}_{2} \mathrm{O}$ was added. (The volume of distilled water added was adjusted to accommodate the volume of each sample aliquot.) Various concentrations ( 1 to 1,000 pM) of unlabeled GABA, in $20-\mu$ l aliquots, were added to tubes to obtain a standard curve. Nonspecific GABA binding was determined by adding excess unlabeled GABA $(2 \mu \mathrm{M})$ to other tubes. When studying GABA receptor binding characteristics $\left(K_{D}\right.$ and $\left.B_{\max }\right)$, the concentration of $\left[{ }^{3} \mathrm{H}\right] \mathrm{GABA}$ was varied (1 to $64 \mathrm{nM}$ ).

The binding assay was initiated when $1-\mathrm{ml}$ aliquots of crude synaptic membranes ( 0.3 to $1.2 \mathrm{mg}$ of protein) were incubated at $4^{\circ} \mathrm{C}$ for $7 \mathrm{~min}$ with the above reactions (final reaction volume, $2 \mathrm{ml}$ ) and agitated immediately with a Vortex mixer after adding the tissue. After incubation, the reaction was terminated by centrifugation at 48,000 $\times g$ for $10 \mathrm{~min}$. The supernatant was discarded and the inverted tube was tapped on a paper towel to remove extraneous supernatant from the pellet. This was followed rapidly by a 5-, then $10-\mathrm{ml}$ rinse of the pellet with ice cold distilled $\mathrm{H}_{2} \mathrm{O}$; care was taken not to dislodge the pellet and to allow only brief but complete contact between the water and the pellet. This was done to wash away nonspecifically bound $\left[{ }^{3} \mathrm{H}\right] \mathrm{GABA}$ and to minimize dissociation of specifically bound $\left[{ }^{3} \mathrm{H}\right] \mathrm{GABA}$. After rinsing, the tubes were turned upside down and permitted to drain (10 min to $1 \mathrm{hr}$ ). Next, a hemostat wrapped by gauze or Kimwipes was placed into each tube to remove all excess fluid without touching the pellet. Bound radioactivity was extracted in $1 \mathrm{ml}$ of protosol (New England Nuclear) and allowed to dissolve either overnight or at $37^{\circ} \mathrm{C}$ for $45 \mathrm{~min}$. Afterward, $10 \mathrm{ml}$ of liquid scintillation cocktail was added and the radioactivity was counted.

Specific $\left[{ }^{3} \mathrm{H}\right] \mathrm{GABA}$ binding was obtained by subtracting from the total bound radioactivity the amount not displaced by high concentrations of unlabeled GABA (2 $\mu \mathbf{M})$. When the GABA receptor binding characteristics ( $K_{D}$ and $B_{\max }$ ) were examined, nonspecific binding was determined for each substrate concentration used. 'This value was subtracted from total binding obtained at each GABA concentration and used as specific binding.

Preliminary time course experiments indicated that specific $\left[{ }^{3} \mathrm{H}\right] \mathrm{GABA}$ binding reached equilibrium by $3 \mathrm{~min}$ and remained constant for more than 14 min when $1 \mathrm{nM}$ $\left[{ }^{3} \mathrm{H}\right] \mathrm{GABA}$ was used. Hence, a 7 -min incubation time was used in all studies. Also, specific $\left[{ }^{3} \mathrm{H}\right] \mathrm{GABA}$ binding was linear up to at least $1.5 \mathrm{mg}$ of protein at the lowest and highest concentrations of $\left[{ }^{3} \mathrm{H}\right] \mathrm{GABA}$. All experiments in this study used between 0.3 and $1.2 \mathrm{mg}$ of protein. Specific $\left[{ }^{3} \mathrm{H}\right]$ CABA binding was saturable at 64 nM GABA. Kinetic assessment of the GABA postsynaptic binding characteristics, $K_{D}$ and $B_{\max }$, was made according to Scatchard plot analysis (Scatchard, 1949) and levels of significance were calculated by the Student's Independent Sample unpaired $t$ test.

\section{Results}

Effects of cobalt or copper implantation on glutamic acid decarboxylase activity. GAD activity was assayed in crude mitochondrial synaptosomal $\left(\mathrm{P}_{2}\right)$ fractions from tissue adjacent to cobalt lesions 1, 7, and 21 days after surgery and was reduced maximally to $25 \%$ of glass controls by 7 days; no reduction in enzyme activity was observed at 1 or 21 days (Fig. 1). Although no attempts were made to quantify the incidence of seizures in the present study, 7 days corresponds to the reported time of maximal seizure activity after cobalt administration (Colasanti et al., 1974; Craig et al., 1976b).

No significant difference in GAD activity was observed between copper-treated rats and glass-implanted controls 1,7 , or 21 days after surgery (Fig. 2).

Effects of cobalt or copper implantation on GABA concentration. GABA levels were measured in crude synaptic membranes from tissue adjacent to the cobalt or copper lesion 1, 7, and 21 days after surgery. No depression of GABA levels was observed after 1 and 21 days, although levels were reduced maximally to $47 \%$ of glass controls 7 days after cobalt treatment (Fig. 3). No 


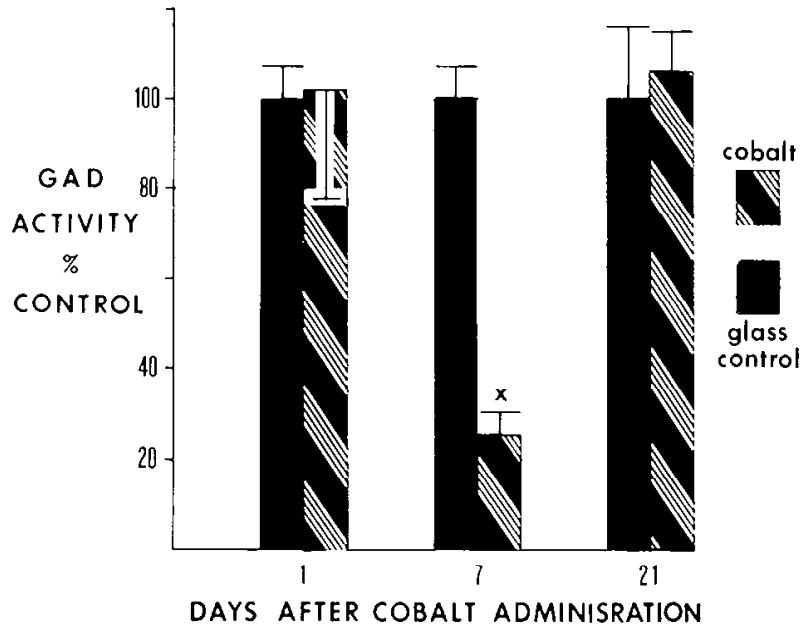

Figure 1. Changes in glutamic acid decarboxylase activity in the rat frontal cerebral cortex adjacent to the cobalt lesion, relative to glass controls 1,7 , and 21 days after cobalt implantation. GAD experiments were done in crude mitochondrial synaptosomal $\left(\mathrm{P}_{2}\right)$ fractions with $4 \mu \mathrm{M}\left[{ }^{14} \mathrm{C}\right]$ glutamic acid and excess cold glutamate and appropriate cofactors. 'The tissue was incubated in a closed system $\left({ }^{14} \mathrm{CO}_{2}\right.$ trapping technique; see "Materials and Methods") for $30 \mathrm{~min}$ at $37^{\circ} \mathrm{C}$ in a shaking water bath. Each value represents the mean of at least 8 but no more than 14 experiments. Vertical bars, SEM; $\times, p<0.01$.

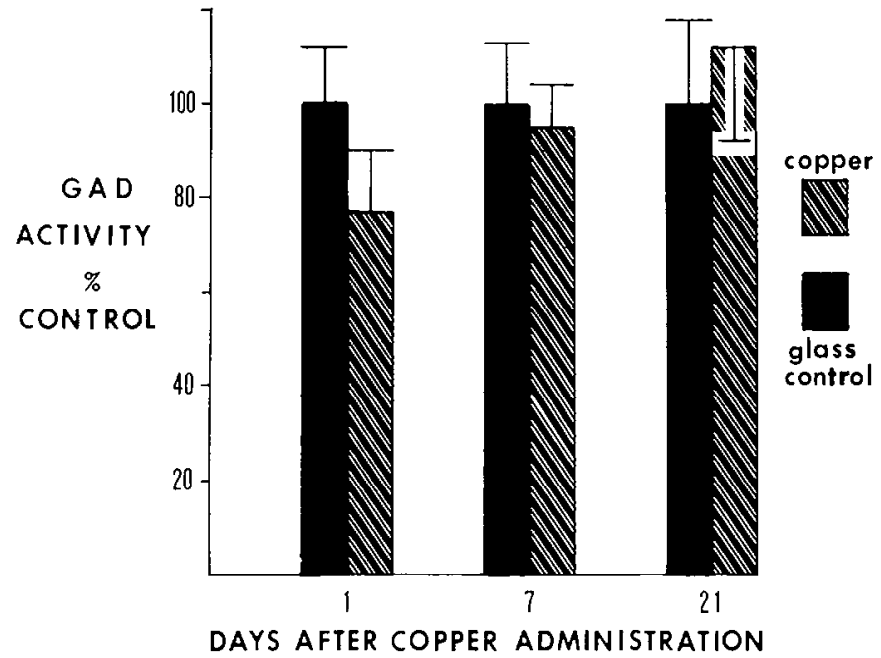

Figure 2. Glutamic acid decarboxylase activity in the rat frontal cerebral cortex adjacent to the copper lesion, relative to glass controls 1,7 , and 21 days following cobalt implantation. GAD experiments were done in the exact same manner as the studies illustrated in Figure 1 and detailed under "Materials and Methods" with the exception that copper metal was implanted into cerebral cortices. Each value represents the mean of 6 to 10 experiments. Each experiment was run in duplicate. Vertical bars, SEM.

reduction in GABA levels from tissue adjacent to the copper or glass lesion was observed throughout the entire 21-day time course (Fig. 4).

Effect of coball or copper implanlation on postsyn. aptic GABA receptor binding characteristics. High affinity GABA receptor binding characteristics $\left(K_{D}\right.$ and $B_{\max }$ ) were examined in crude synaptic membranes from rats treated with cobalt, copper, or glass from tissue adjacent to the lesion but excluding any visually necrotic tissue. These studies were conducted 1,7 , and 21 days after cobalt and 7 days after copper implantation, re-

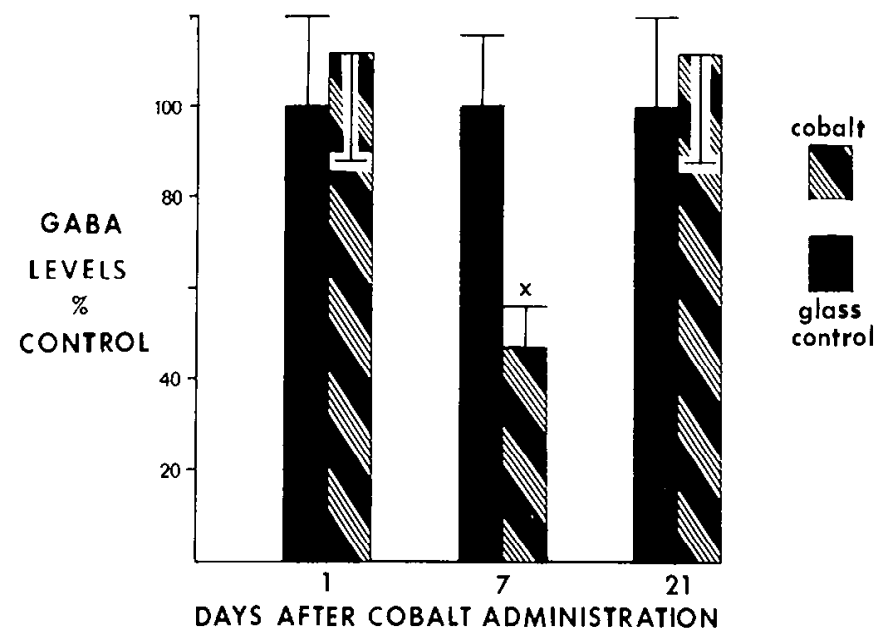

Figure 3. Reduction in GABA levels in the rat frontal cerebral cortex adjacent to the cobalt lesion, relative to glass controls after 7 days. The determination of GABA levels necessitates killing the animals by microwave irradiation, dispersal of the tissue with a Polytron, and centrifuging the tissue. An aliquot of the supernatant was utilized for the assay. A radioligand assay was used in which, in the presence of various concentrations of unlabeled GABA, the $\left[{ }^{3} \mathrm{H}\right] \mathrm{GABA}$ remaining specifically bound to crude synaptic membrane fragments is proportional to the logarithm of the added GABA (sample). For the binding assay, $8 \mathrm{~nm}\left[{ }^{3} \mathrm{H}\right] \mathrm{GABA}$ was used routinely. Further details of the procedure are provided under "Materials and Methods." Each value represents the mean of 6 to 10 experiments. Each experiment was run in triplicate. Vertical bars, SEM; $\times, p<0.05$.

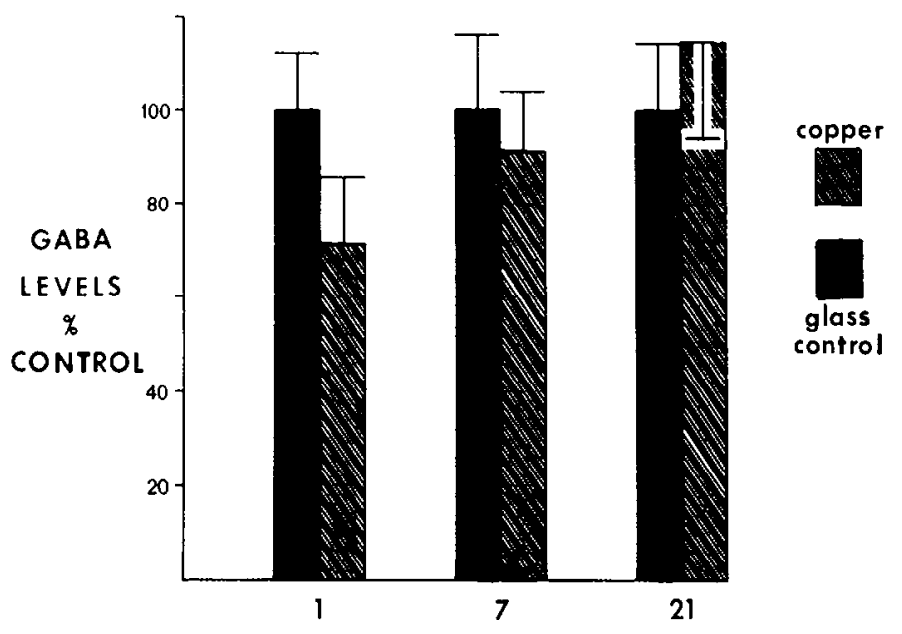

DAYS AFTER COPPER ADMINISTRATION

Figure 4. GABA levels in the rat frontal cerebral cortex adjacent to the copper lesion, relative to glass controls 1,7 , and 21 days after implantation. These experiments were carried out in the exact same manner as the study illustrated in Figure 3 and detailed under "Materials and Methods" with the exception that the effects of copper were examined rather than cobalt. Each value represent the mean of 5 to 7 experiments. Each experiment was run in triplicate. Vertical bars, SEM. 


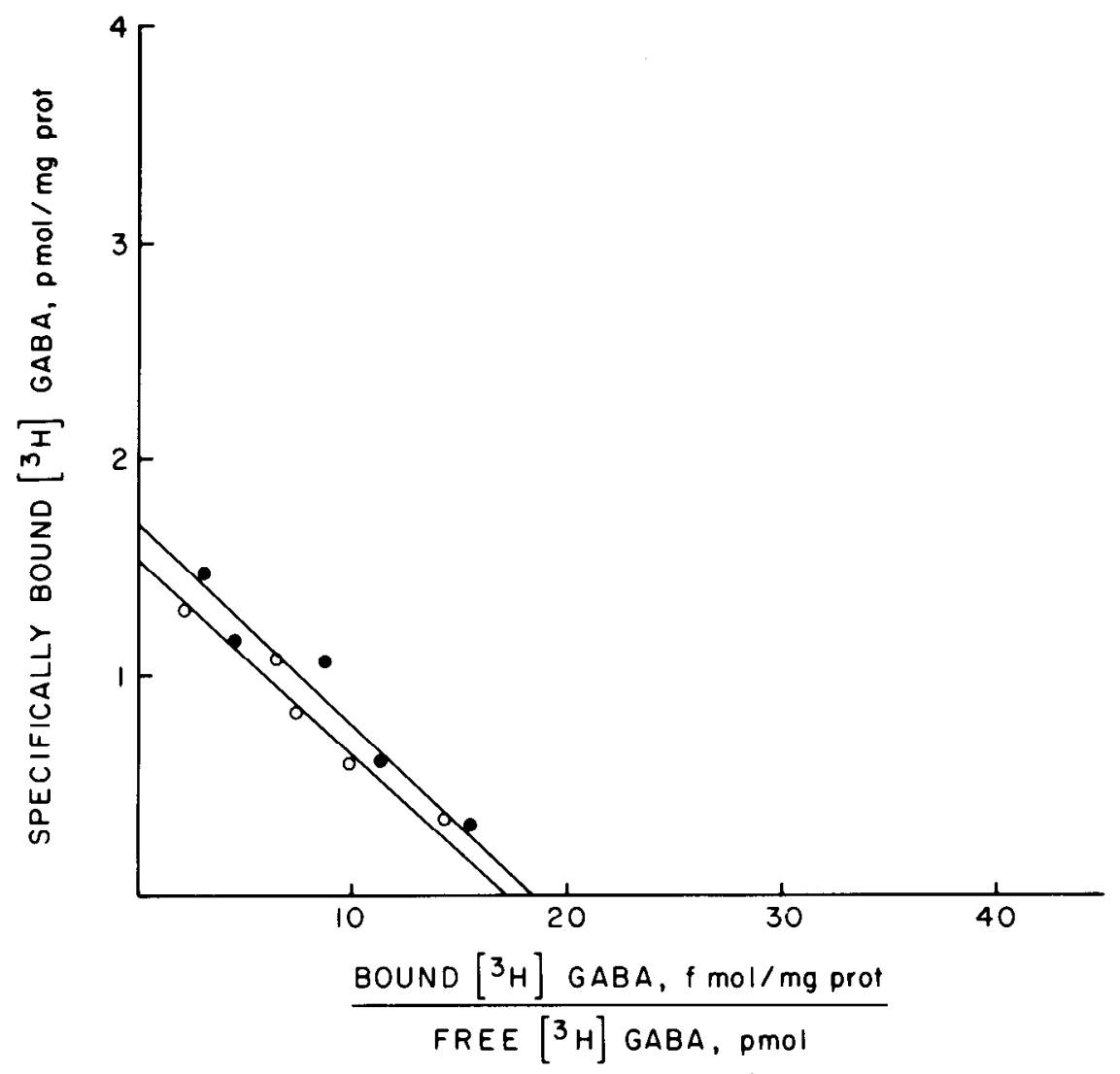

Figure 5. Scatchard plot analysis of the binding of $\left[{ }^{3}\right.$ II]GABA to frozen Triton $\mathrm{X}-100$-treated crude synaptic membrane preparations from the rat frontal cerebral cortex adjacent to the cobalt or glass implant 1 day after implantation. Specific $\left[{ }^{3} \mathrm{H}\right]$ GABA binding was determined at $4^{\circ} \mathrm{C}$ in $\mathrm{Na}^{+}$-free media at various concentrations of $\left[{ }^{3} \mathrm{H}\right] \mathrm{GABA}$. Nonspecific $\left[{ }^{3} \mathrm{H}\right] \mathrm{GABA}$ binding was obtained with $2 \mu \mathrm{M}$ unlabeled GABA. Details are provided under "Materials and Methods." $O$, Glass controls; $\mathbf{Q}$, cobalt data.

spectively. No alteration in affinity $\left(K_{D}\right)$ or the number of postsynaptic binding sites $\left(B_{\max }\right.$ ) was observed using Scatchard plot analysis 1 day after cobalt insult compared to glass controls (Fig. 5). Seven days after cobalt implantation, no change in $K_{D}$ was noted as evidenced by the parallel linear regression lines of the cobalt or glass Scatchard plots, but an increase of about $200 \%$ in the number of postsynaptic GABA binding sites $\left(B_{\max }\right)$ was observed after cobalt treatment in comparison with glass treatment after extrapolation of the cobalt and glass data to the $y$ axis (Fig. 6). Scatchard analysis of copperand glass-treated tissue 7 days after surgery revealed no alteration in the affinity when compared to 7-day glass controls, and in contrast to the 7-day cobalt study, no significant difference in the $B_{\max }$ was observed in 7-day copper-treated tissue adjacent to the lesion (Fig. 6). No modification of the slopes of the linear regression line $\left(K_{D}\right)$ was observed in glass- or cobalt-treated tissue 14 days after treatment although an apparent increase in $B_{\max }$ was noted in cobalt-treated rats (not shown). After 21 days, the affinity of the postsynaptic GABA receptor for GABA had not changed, yet an apparent increase in the number of binding sites $\left(B_{\max }\right)$ was still evident in cobalt-treated tissues adjacent to the lesion (Fig. 7), although this apparent increase in specific $\left[{ }^{3} \mathrm{H}\right] \mathrm{GABA}$ $\left(B_{\max }\right)$ binding was qualitatively less than after 7 and 14 days.
Table I lists the $K_{D}$ and $B_{\max }$ values obtained for high affinity postsynaptic GABA receptor binding to crude synaptic membranes of tissue adjacent to the lesion from cobalt-, copper-, or glass-treated rats 1 and 21 days following application. On day 7 , a significant increase was observed in the postsynaptic binding sites $\left(B_{\max }\right)$ of cobalt-treated rats versus 7-day glass controls. No increase in $B_{\max }$ was recorded in 7-day copper-treated rats. After 14 and 21 days, an apparent increase in $B_{\max }$ was noted in cobalt-treated tissue, although these observations were not statistically significant.

\section{Discussion}

The chronic model of epilepsy produced by cerebral cortical cobalt application to the rat shares many characteristics with human cortical epilepsy; the chronic state produced by cobalt is characterized by a low seizure threshold to chemical convulsants, EEG abnormalities, neurochemical and morphological alterations similar to those in human epilepsy, spontaneous paroxysmal motor activity, and interictal periods of no seizure activity.

The purpose of this study was to investigate the integrity of the GABA neuron in the cobalt-epileptic rat. Since GABA is a major inhibitory neurotransmitter in the CNS, disruption of its metabolism could conceivably lead to relatively uncontrolled pyramidal cell-firing episodes in the frontal cortex and, consequently, epileptic activity 


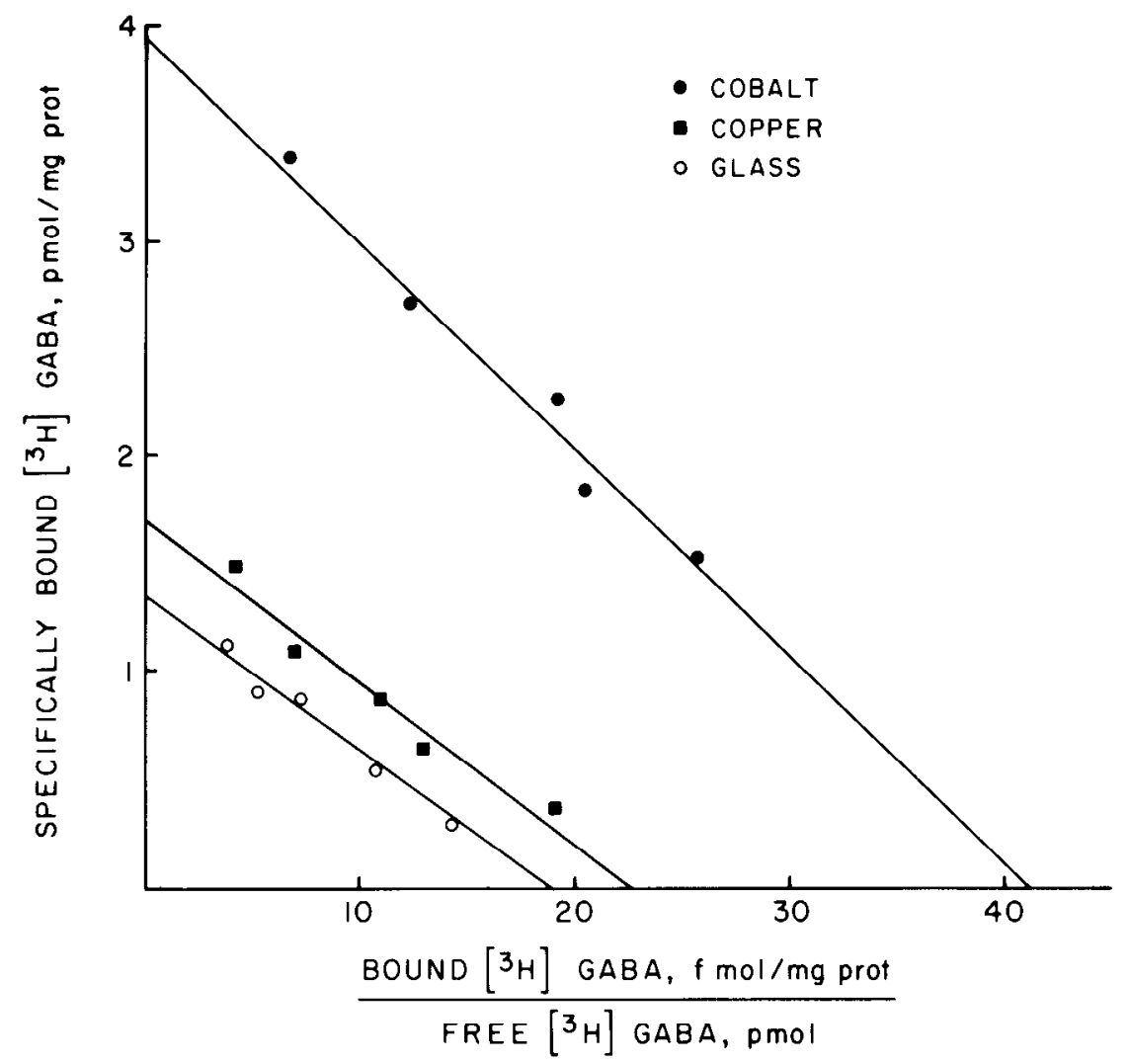

Figure 6. Scatchard plot analysis showing an increase in specific $\left[{ }^{3} \mathrm{H}\right] \mathrm{GABA}$ binding to the frontal adjacent cortical preparations in cobalt-treated tissue but not in copper tissue relative to glass controls 7 days after implantation. No change in affinity $\left(K_{D}\right)$ occurs after any treatment. Each value represents the mean of 6 to 9 separate experiments. Each experiment represents the frontal cerebral cortex pooled from seven rats and was run in duplicate. Further details are discussed under "Materials and Methods."

manifested as seizures and convulsions as the functional end point of the neuropathology.

It is clear from this and other studies that GABAergic mechanisms are perturbed during the epileptogenic process induced by implantation of cobalt in the cortex of the rat. Results from our previous study (Ross and Craig, 1981) indicated that high affinity GABA uptake was disrupted during cobalt-induced epilepsy as evidenced by depressed $V_{\max }$ values during periods of peak seizure activity in this model ( 7 days) and returned to control values at a time when seizures had essentially stopped (21 days). The decrease in $V_{\max }$ may be a reflection of the loss of neuronal elements and the return to control levels may represent regeneration of damaged neurons.

The enzyme glutamic acid decarboxylase (GAD) is localized to the GABAergic nerve terminal and is the rate-limiting enzyme in the synthesis of GABA. In addition to high affinity GABA uptake, GAD activity has been used as an index of GABA nerve terminal viability and function. The activity of this enzyme was measured in the primary focus of tissue adjacent to the lesion 1 to 21 days after either cobalt, copper, or glass implantation. Results from this study indicated that GAD activity was reduced maximally to $25 \%$ of that in glass controls in cortical tissue of epileptic rats during a period of peak seizure activity (7 days) and returned to glass control values at 21 days. Implantation of glass or copper, how- ever, produced no change in GAD activity adjacent to the lesion throughout the entire time course of the study. Consequently, the results of this study provide further evidence that cobalt altered GABAergic transmission, in this case, through reduction of the conversion of glutamate to GABA.

The third criterion used to establish the integrity and viability of the GABA nerve terminal in the frontal cerebral cortex utilized a radioligand assay to determine GABA levels in primary focal tissue of cobalt-epileptic rats and tissue from copper- and glass-treated animals. Again, a similar biochemical profile was elicited; GABA levels in cobalt-epileptic tissue were depressed maximally to $47 \%$ of glass controls after 7 days and returned to control levels at 21 days. This finding also supports the contention that the functional integrity of the GABA neuron is impaired in cobalt epilepsy and the return toward controls suggests that reparative processes are active.

High affinity GABA uptake, GAD activity, and GABA levels are all measures of GABAergic nerve terminal viability, function, and integrity. The compiled evidence suggests that the GABA nerve terminal in the rat frontal cerebral cortex is functionally decreased during the period of seizure activity in this model. Also, all GABA parameters analyzed return to control values at a time when seizures have essentially stopped or decreased. The 


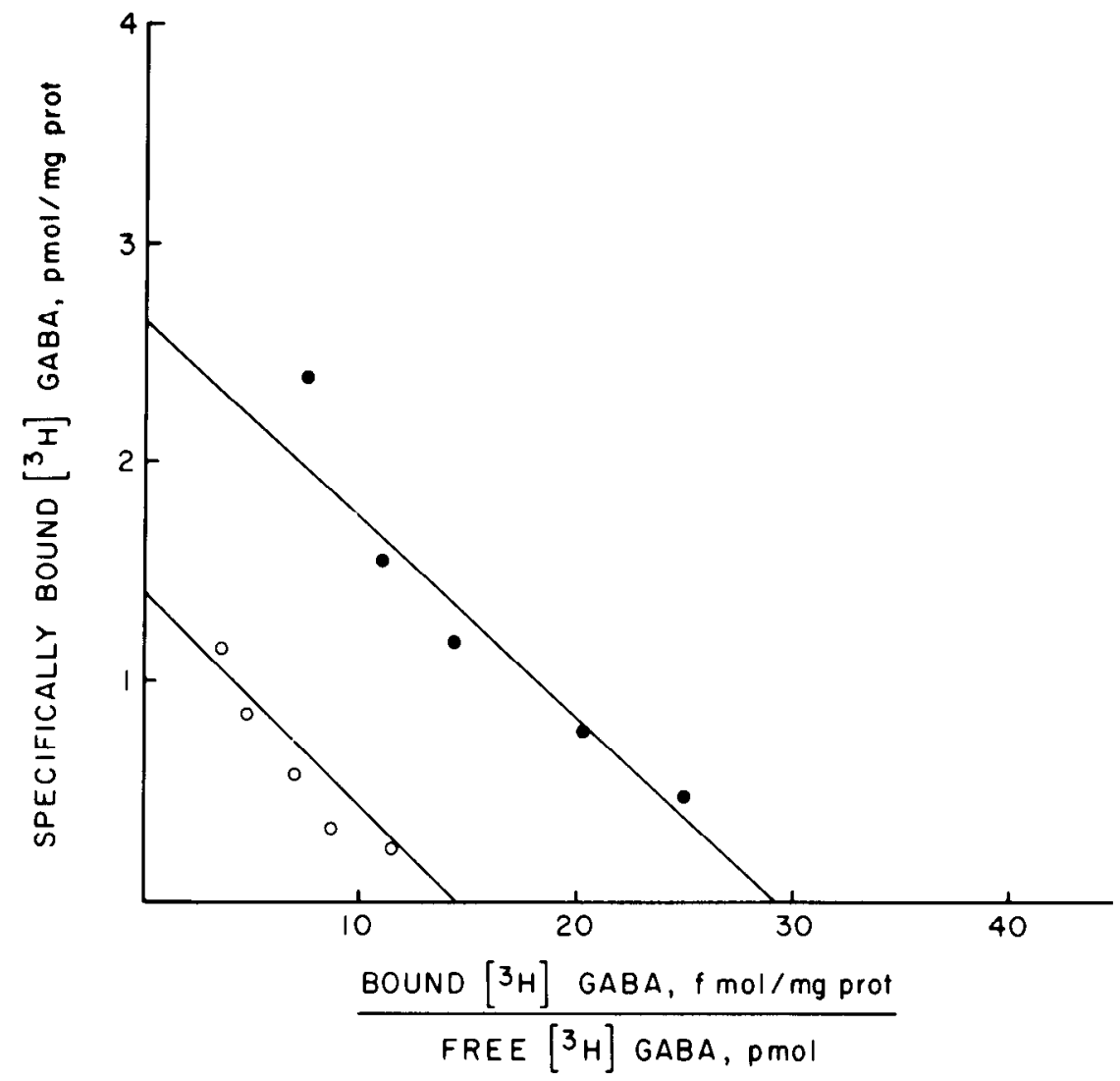

Figure 7. Scatchard plot depicting specific I ${ }^{3} \mathrm{H}$ JGABA binding 21 days after cobalt and glass pretreatment. An apparent increase in $B_{\max }$ was noted in cobalttreated tissue compared to glass controls. No alteration in affinity of the GABA receptor for $\left[{ }^{3} \mathrm{H}\right] \mathrm{GABA}$ was observed at this time period. Each value represents the mean of 6 to 7 experiments and each $n$ was comprised of pooled adjacent cortical tissue from seven rats. The methods used were exactly as previously described in Figures 5 and 6 and under "Materials and Methods." $O$, Glass controls; 9 , cobalt data.

TABLE I

Summary of kinetic parameters of GABA postsynaptic receptor binding at various times following application of metal to the frontal cerebral cortex

\begin{tabular}{|c|c|c|c|c|c|}
\hline & \multirow{2}{*}{ Treatment } & \multicolumn{4}{|c|}{ Days following Metal Application } \\
\hline & & 1 & 7 & 14 & 21 \\
\hline & & & & & \\
\hline & $\begin{array}{l}\text { Glass } \\
\quad \text { (control) }\end{array}$ & $8.20 \pm 0.36$ & $5.56 \pm 0.74$ & $10.60 \pm 3.4$ & $9.36 \pm 0.99$ \\
\hline & Copper & & $8.69 \pm 1.92$ & & \\
\hline & & & & protein & \\
\hline \multirow{4}{*}{$B_{\max }$} & Cobalt & $1.68 \pm 0.20^{a}$ & $3.97^{b} \pm 0.83$ & $3.32 \pm 0.79$ & $2.64 \pm 0.35$ \\
\hline & $\begin{array}{l}\text { Glass } \\
\quad \text { (control) }\end{array}$ & $1.52 \pm 0.21^{a}$ & $1.36 \pm 0.17$ & $1.64 \pm 0.32$ & $1.41 \pm 0.22$ \\
\hline & Copper & & $1.74 \pm 0.25$ & & \\
\hline & $\begin{array}{l}\text { Glass } \\
\quad \text { (control) }\end{array}$ & & $1.55 \pm 0.28$ & & \\
\hline
\end{tabular}

$$
" \pm \mathrm{SEM} \text {. }
$$

${ }^{b} p<0.05$.

latter evidence supports the hypothesis that regeneration of GABA nerve terminals, or at least recovery of function of GABAergic nerve transmission, has returned when few seizures or convulsions are evident.
The fact that copper metal does not alter GAD activity, GABA levels, or high affinity GABA uptake in tissue adjacent to the lesion 7 days after surgery supports previous observations that this element is non-epilepto- 
genic (Hartman et al., 1974; Chusid and Kopeloff, 1962). Copper does, however, evoke a more rapid, extensive gliosis followed by glial proliferation in tissue adjacent to the lesion than does cobalt (Hoover et al., 1977b). Cellular edema and perivascular exudation have been observed in adjacent cortex in cobalt-, copper-, and alumina-implanted animals (Payan, 1967; Chang and Payan, 1979). Consequently, since copper is non-epileptogenic, these changes could be considered traumatic changes of a nonspecific nature and have no influence with regard to the epileptogenicity of cobalt (Chang and Payan, 1979). Since copper failed to alter any GABA parameters as assessed in this study, but cobalt lowered GAD, GABA levels, and high affinity GABA uptake, these data provide further evidence, albeit indirect, that GABA plays a role in experimental epilepsy.

Five to 10 days after implantation of cobalt roughly corresponds to a period of peak seizure activity in this model seizure state. GAD activity and high affinity GABA uptake were reduced to $25 \%$ and $34 \%$ of controls, respectively, in tissue adjacent to the cobalt lesion after 7 days. However, GABA levels were reduced maximally to only $47 \%$ of controls over this same time period. This relative discrepancy may be accounted for by the observation that GABA is known to accumulate in glial and other extraneuronal structures (Bloom and Iversen, 1971; Iversen and Kelly, 1975), whereas GAD activity and high affinity GABA uptake are processes localized to the GABA nerve terminal (Ribak et al., 1979; Iversen and Bloom, 1972; Iversen and Kelly, 1975). Since we demonstrated that low affinity GABA uptake is unaffected during cobalt epilepsy (Ross and Craig, 1981), it is possible that the relatively higher levels of GABA compared to GAD activity and high affinity GABA uptake may be the result of the localization of GABA in glial (extraneuronal) structures.

There is also evidence of an increase over control in glial elements in the primary focal area after cobalt treatment (Hoover et al., 1977b). 'This evidence, coupled with the work of Bond (1973) who demonstrated varied tissue localization of low and high affinity GABA uptake, has led to the hypothesis that glial structures, may be responsible, in part, for the accumulation of GABA by the low affinity uptake process (Iversen and Bloom, 1972; Bloom and Iversen, 1971; Iversen and Kelly, 1975).

High affinity radioactive ligand assays have become available to estimate the number of receptors and the affinity of the receptor for the ligand. Since important indications of GABA neuronal function, such as high affinity GABA uptake, GAD activity, and GABA concentration, are depressed during periods of intense seizure activity, this suggests possible denervation of the GABA neuron in the rat cerebral cortex after cobalt insult. Consequently, we examined postsynaptic GABA receptor binding characteristics in the rat frontal cortex after cobalt, copper, and glass administration in order to determine if any brain adaptative responses are operative during the epileptogenic process induced by cobalt implantation. Our results indicate that postsynaptic receptor density was increased markedly during the time of maximal seizure activity in the cobalt-epileptic rat. Comparable findings have been observed by other investigators who have studied postsynaptic receptors during sei- zure states after kindling, electroshock, and pentylenetetrazol (Paul and Skolnick, 1978; Byrne et al., 1980; McNamara, 1978; McNamara et al., 1980). The increment of change in receptor density observed in the studies cited was much less than in the present findings; the dramatic increase in GABA receptor density that we observed is greater than anything presented in the literature thus far. Possible explanations for the massive increase in $B_{\max }$ are a high turnover rate of the GABA receptor during cobalt epilepsy, the use of an agonist $\left(\left[{ }^{3} \mathrm{H}\right] \mathrm{GABA}\right)$ as the ligand rather than the traditionally used antagonist (there is presently no pure postsynaptic GABA antagonist), or nonspecific cobalt ion-induced change in the postsynaptic membrane during the seizure state which elicits a large increase in GABA receptor number.

In summary, these results provide additional evidence for a role for GABA in seizure disorders. Key GABA indices of nerve terminal viability and function are maximally depressed during periods of peak seizure activity in this model seizure state, yet these parameters return to control values when seizures have essentially stopped. This evidence suggests that periods following cobalt administration when seizures are no longer present may be a result of the return of normal GABAergic transmission through regeneration of the GABA nerve terminal in the frontal cerebral cortex of the cobalt-epileptic rat. The enhancement of postsynaptic GABA receptor binding observed at 7 days may reflect an attempt to maintain normal neuronal homeostasis by increasing the physiological effects of GABA and may represent a CNS "denervation supersensitivity" phenomenon. Denervation supersensitivity in the CNS has been demonstrated by Ungerstedt et al. (1975) who showed a supersensitivity of dopamine receptors to dopamine agonists following lesions of the nigrostriatal pathway. An increase in sensitivity to noradrenaline also has been demonstrated after intraventricular 6-hydroxydopamine (Huang et al., 1973), electrolytic destruction of the medial forebrain bundle (Dismukes et al., 1975), and reserpine pretreatment (Dismukes and Daly, 1974). The reduction in postsynaptic GABA receptor binding at 21 days compared to binding at 7 days is consistent with regeneration of the GABAergic nerve terminal and the consequent return of "normal" GABAergic nerve transmission by approximately 21 days.

\section{References}

Altamura, A. C., M. Bonati, N. Brunello, P. L. Giordano, and S. Algeri (1978) The activity of some neurotransmitter-synthesizing enzymes in experimental cobalt epilepsy. Neurosci. Lett. 7: 83-87.

Bloom, F. E., and L. L. Iversen (1971) Localizing ${ }^{3} \mathrm{H}-\mathrm{GABA}$ in nerve terminals of rat cerebral cortex by electron microscopic autoradiography. Nature 229: 628-630.

Bond, P. A. (1973) The uptake of $\gamma-\left({ }^{3} \mathrm{H}\right)$ aminobutyric acid by slices from various regions of rat brain and the effect of lithium. J. Neurochem. 20: 511-517.

Byrne, M. C., R. Gottlieb, and J. O. McNamara (1980) Amygdala kindling induces muscarinic cholinergic receptor declines in a highly specific distribution within the limbic system. Exp. Neurol. 69: 85-98.

Chang, L. W., and H. M. Payan (1979) Cobalt induced epilepsy: An ultrastructural study. Neurol. Res. 1: 19-29. 
Chusid, J. G., and L. M. Kopeloff (1962) Epileptogenic effects of pure metals implanted in motor cortex of monkeys. J. Appl. Physiol. 17: 696-700.

Colasanti, B. K., E. R. Hartman, and C. R. Craig (1974) Electrocorticogram and behavioral correlates during the development of chronic cobalt experimental epilepsy in the rat. Epilepsia 15: 361-373.

Craig, C. R., and E. R. Hartman (1973) Brain amino acid concentrations in the cobalt-epileptic rat. Epilepsia 14: 409414.

Craig, C. R., P. Chiu, and B. K. Colasanti (1976a) Effects of diphenylhydantoin and trimethadione on seizure activity during cobalt experimental epilepsy in the rat. Neuropharmacology 15: 485-489.

Craig, C. K., D. B. Hoover, and B. K. Colasanti (1976b) Appearance of epileptiform activity in the rat after bilateral cerebral implantation of cobalt. Pharmacologist 18: 127.

Dismukes, K., and J. W. Daly (1974) Norepinephrine-sensitive systems generating adenosine $3^{\prime}: 5^{\prime}$-monophosphate: Increased responses in cerebral cortical slices from reserpinetreated rats. Mol. Pharmacol. 10: 933-940.

Dismukes, R. K., P. Ghosh, C. R. Creveling, and J. W. Daly (1975) Altered responsiveness of adenosine $3^{\prime}: 5^{\prime}$-monophosphate generating systems in rat cortical slices after lesions of the medial forebrain bundle. Exp. Neurol. 49: 725-735.

Emson, P. C., and M. H. Joseph (1975) Neurochemical and morphological changes during the development of cobaltinduced epilepsy in the rat. Brain Res. 93: 91-110.

Enna, S. J., and S. H. Snyder (1977) Influence of ions, enzymes and detergents on $\gamma$-aminobutyric acid receptor binding in synaptic membranes of rat brain. Mol. Pharmacol. 13: 442453.

Goldberg, A. M., J. J. Pollock, E. R. Hartman, and C. R. Craig (1972) Alterations in cholinergic enzymes during the development of cobalt-induced epilepsy in the rat. Neuropharmacology 11: 253-259.

Hartman, E. R., B. K. Colasanti, and C. R. Craig (1974) Epileptogenic properties of cobalt and related metals applied directly to cerebral cortex of rat. Epilepsia 15: 121-129.

Hoover, D. B., C. R. Craig, and B. K. Colasanti (1977a) Cholinergic involvement in cobalt-induced epilepsy in the rat. Exp. Brain Res. 29: 501-513.

Hoover, D. B., J. L. Culberson, and C. R. Craig (1977b) Structural changes in cerebral cortex during cobalt-induced epilepsy in the rat. Neurosci. Lett. 4: 275-280.

Huang, M., A. K. S. Ho, and J. W. Daly (1973) Accumulation of adenosine cyclic $3^{\prime}: 5^{\prime}$-monophosphate in rat cerebral cor- tical slices. Mol. Pharmacol. 19: 711-717.

Iversen, L. L., and F. E. Bloom (1972) Studies of the uptake of ${ }^{3} \mathrm{H}$-GABA and ${ }^{3} \mathrm{H}$-glycine in slices and homogenates of rat brain spinal cord by electron microscopic autoradiography. Brain Res. 41: 131-143.

Iversen, L. L., and J. S. Kelly (1975) Uptake and metabolism of $\gamma$-aminobutyric acid by neurones and glial cells. Biochem. Pharmacol. 24: 933-938.

Koyama, I. (1972) Amino acids in the cobalt-induced epileptogenic and non-epileptogenic cat's cortex. Can. J. Physiol. Pharmacol. 50: 740-752.

McNamara, J. O. (1978) Selective alterations of regional $\beta$ adrenergic receptor binding in the kindling model of epilepsy. Exp. Neurol. 61: 582-591.

McNamara, J. O., A. M. Peper, and V. Patrone (1980) Repeated seizures induce long-term increase in hippocampal benzodiazepine receptors. Proc. Natl. Acad. Sci. U. S. A. 77: 30293032.

Paul, S. M., and P. Skolnick (1978) Rapid changes in brain benzodiazepine receptors after experimental seizures. Science 202: 892-893.

Payan, H. M. (1967) Cerebral lesions in rats by various implants: Epileptogenic effect of cobalt. J. Neurosurg. 27: 146-152.

Ribak, C. E., H. B. Harris, J. E. Vaughn, and E. Roberts (1979) Inhibitory GABA-ergic nerve terminals decrease as sites of focal epilepsy. Science 205: 211-214.

Ross, S. M., and C. R. Craig (1981) Studies on GABA transport in cobalt experimental epilepsy in the rat. J. Neurochem. 36 : 1006-1011.

Scatchard, G. (1949) The attraction of protein for small molecules and ions. Ann. N. Y. Acad. Sci. 51: 660-672.

Ungerstedt, U., T. Ljungberg, B. Hoffer, and G. Siggins (1975) Dopaminergic supersensitivity in the striatum. Adv. Neurol. 9: 57-65.

Van Duijn, H., and S. L. Visser (1972) The action of some anticonvulsant drugs on cobalt-induced epilepsy and on the bemegride threshold in alert cats. Epilepsia 13: 409-420.

Van Gelder, N. M. (1974) Glutamate dehydrogenase, glutamic acid decarboxylase, and GABA aminotransferase in epileptic mouse cortex. Can. J. Physiol. Pharmacol. 52: 952-959.

Van Gelder, N. M., and A. Courtois (1972) Close correlation between changing content of specific amino acids in epileptogenic cortex of cats, and severity of epilepsy. Brain Res. 43: 477-484.

Van Gelder, N. M., A. L. Sherwin, and T. Rasmussen (1972) Amino acid content of epileptogenic human brain. Focal versus surrounding regions. Brain Res. 40: 385-393. 